\title{
Effect of Short-Term, Low-Level Nitrogen Dioxide Exposure on Bronchial Sensitivity of Asthmatic Patients
}

\author{
J. Orehex, J. P. Massari, P. Gayrard, C. Grimaud, and J. Charpin \\ From the Laboratoire d'Explorations Fonctionnelles Respiratoires, the Laboratoire de \\ Toxicologie Générale et Biotoxicologie, and the Clinique de Pneumo-Phtisiologie, \\ Hôpital Sainte-Marguerite, Marseille Cedex 2, France
}

A B S T R A C T Our purpose was to determine whether exposure to a realistic concentration of nitrogen dioxide $\left(\mathrm{NO}_{2}\right)$ could increase the bronchial sensitivity of asthmatic patients to bronchoconstrictor agents. We established dose-response curves for changes in specific airway resistance ( $\mathrm{SR}_{\mathrm{aw}}$ ) in response to aerosolized carbachol in 20 asthmatics after each had spent $1 \mathrm{~h}$ in an exposure chamber breathing on one occasion unpolluted air and on a separate occasion $0.1 \mathrm{ppm} \mathrm{NO}_{2}$ : sequence of exposures to unpolluted air and to low levels of $\mathrm{NO}_{2}$ were randomized in a single-blind fashion. $\mathrm{NO}_{2}$ induced a slight but significant increase in initial SRaw and enhanced the bronchoconstrictor effect of carbachol in 13 subjects: curves were shifted to the left and the mean dose of carbachol producing a twofold increase in initial SRaw was decreased from $0.66 \mathrm{mg}$ to $0.36 \mathrm{mg} \quad(P<$ $0.001)$. In contrast, $\mathrm{NO}$, neither modified the initial $\mathrm{SR}_{\mathrm{aw}}$ nor the bronchoconstrictor effect of carbachol in seven subjects. In 4 out of the 20 subjects, exposure to a higher concentration of $\mathrm{NO}_{2}(0.2 \mathrm{ppm})$ yielded variable results.

Potentiation of the carbachol bronchoconstrictor response by NO, could not be related to any physical or clinical characteristics of the subjects tested. Although the mechanisms underlying the $\mathrm{NO}_{2}$ effect remain controversial, the present results demonstrate that very low levels of $\mathrm{NO}_{2}$ can adversely affect some asthmatics.

\section{INTRODUCTION}

Epidemiological studies have suggested there is a relationship between air pollution and the prevalence and severity of asthma as well as chronic pulmonary diseases in general (for review see references 1-4). However, the role of air pollution is still questioned since in ex-

Received for publication 30 June 1975 and in revised form 7 October 1975. periments with controlled exposures, air pollutants exert a detectable effect on lung function only at concentrations that exceed those commonly observed in urban polluted atmosphere. To our knowledge very few of these laboratory studies (5-7) have been performed with asthmatics. These few have demonstrated that asthmatics reacted to smaller doses of pollutants than normal subjects, but the doses used were still higher than those usually encountered in the atmosphere.

In this study we have investigated the direct bronchomotor effect of realistic concentrations of nitrogen dioxide $\left(\mathrm{NO}_{2}\right)$, one of the major air pollutants, in a group of asthmatics. We have also measured the bronchial sensitivity to carbachol before and after $\mathrm{NO}_{2}$ exposure in order to establish whether $\mathrm{NO}_{2}$ could make the airways "hyperreactive."

\section{METHODS}

Subjects. 20 asthmatics volunteered for this study ( $\mathrm{NO}_{2}$ group, Table I). All were outpatients, suffering from slight to mild asthma. They were studied during symptom-free periods and received no symptomatic medication for at least $24 \mathrm{~h}$ beforehand. None of these subjects was undergoing long-term steroid therapy and all of them lived in an urban area.

Airway resistance $\left(R_{a w}\right)^{1}$ measurements. We recorded simultaneously $R_{\mathrm{aw}}$ and thoracic gas volume (TGV;8) with a constant volume body plethysmograph (DR-8 amplifier-recorder, Electronics for Medicine, Inc., White Plains, N. Y.). The subject panted at a frequency of 2 cycles $/ \mathrm{s}$ and a flow rate of 0.5 liter/s (9). The results were expressed as specific airway resistance, $\mathrm{SR}_{\mathrm{aw}}=\mathrm{R}_{\mathrm{aw}} \times \mathrm{TGV}$, (expressed in centimeters of water $\times$ second) which is preferable to the use of specific airway conductance (10).

$N O$, exposure. Cylinders of $0.01 \% \mathrm{NO}_{2}$ in nitrogen were obtained commercially as the source of $\mathrm{NO}_{2}$ (Compagnie Française des Produits Oxygénés, Paris). A volume of gas, calculated to give a concentration of $\mathrm{NO}_{2}$ approximatively

${ }^{1}$ Abbreviations used in this paper: $\mathrm{D}_{100}$, the dose of carbachol causing a $100 \%$ increase of initial $\mathrm{SR}_{\mathbf{a w}} ; \mathrm{R}_{\mathrm{aw}}$, airway resistance; $S R_{a w}$, specific $R_{a w} ; T G V$, thoracic gas volume. 
TABLE I

Physical and Clinical Characteristics of the Asthmatics in the $\mathrm{NO}_{2}$ Group

\begin{tabular}{rllccc}
\hline Subject & $\begin{array}{c}\text { Age }(y r) \\
\text { and sex }\end{array}$ & $\begin{array}{c}\text { Intrinsic (I) or } \\
\text { extrinsic (E) asthma }\end{array}$ & $\begin{array}{c}\text { Duration of } \\
\text { asthma }\end{array}$ & $\begin{array}{c}\text { Severity of } \\
\text { asthma* }\end{array}$ & $\begin{array}{c}\text { Cigarettes } \\
\text { per day }\end{array}$ \\
\hline & & & $y r$ & & \\
1 & $27 \mathrm{M}$ & E (house dust) & 6 & 1 & 10 \\
2 & $44 \mathrm{~F}$ & I & 12 & 1 & 0 \\
3 & $19 \mathrm{~F}$ & E (grass pollen) & 3 & 2 & $6-10$ \\
4 & $20 \mathrm{M}$ & I & $<1$ & 1 & 50 \\
5 & $40 \mathrm{~F}$ & E (grass pollen) & 24 & 1 & 0 \\
6 & $27 \mathrm{M}$ & E (house dust) & 2 & 2 & 0 \\
7 & $35 \mathrm{M}$ & E (house dust) & 4 & 2 & 0 \\
8 & $40 \mathrm{M}$ & E (grass pollen) & 12 & 2 & 13 \\
9 & $20 \mathrm{M}$ & E (weeds pollen) & 14 & 1 & 10 \\
10 & $24 \mathrm{M}$ & E (house dust) & 9 & 1 & 0 \\
11 & $25 \mathrm{~F}$ & E (house dust) & 2 & 2 & 0 \\
12 & $18 \mathrm{M}$ & E (house dust) & 6 & 1 & 10 \\
13 & $16 \mathrm{~F}$ & E (house dust) & $<1$ & 1 & 0 \\
14 & $25 \mathrm{M}$ & I (hense dust) & 2 & 2 & 0 \\
15 & $22 \mathrm{M}$ & E (house & 21 & 1 & 0 \\
16 & $37 \mathrm{~F}$ & I & 12 & 2 & 0 \\
17 & $17 \mathrm{M}$ & E (grass pollen) & 4 & 1 & 0 \\
18 & $15 \mathrm{M}$ & E (moulds) & 2 & 1 & 0 \\
19 & $31 \mathrm{~F}$ & E (grass pollen) & 5 & 1 & 0 \\
20 & $25 \mathrm{M}$ & E (house dust) & 5 & 1 & 0 \\
\hline
\end{tabular}

* Grade 1, less than 8 days of dyspnea yearly; grade 2, less than 60 and more than 8 days of dyspnea yearly.

over $200 \mu \mathrm{g} / \mathrm{m}^{3}$ was allowed to flow into an airtight exposure room. Actual $\mathrm{NO}_{2}$ concentrations were measured by sampling room air with a pump during 15-min intervals with the method of Saltzman (11). The air sampler was close to the subject's face and a fan was used to circulate air within the room. The average concentration (mean $\pm \mathrm{SE}$ for 20 experiments) during the first $15-\mathrm{min}$ interval was $246 \pm 18 \mu \mathrm{g} / \mathrm{m}^{3}$ and decreased regularly: $-10 \%$ for the second interval, $-9 \%$ for the third interval, and $-16 \%$ for the fourth interval. The average concentration during the hour exposure was $210 \mu \mathrm{g} / \mathrm{m}^{3}$, which is approximatively $0.1 \mathrm{ppm}$. In some cases a higher dose of $\mathrm{NO}_{2}$ was used: average concentration of $488 \mu \mathrm{g} / \mathrm{m}^{3}$ (slightly over $0.2 \mathrm{ppm}$ ). None of the subjects reported having detected a particular odor due to the gas.

Carbachol dose-response curves. After measurement of basal $\mathrm{SR}_{\mathrm{aw}}$ (mean of five determinations) a dose-response curve was established for each subject by using a $0.1 \%$ (wt/vol) nebulized solution of carbachol (Merck A.G. Inc., Darmstadt, West Germany) in $0.9 \%$ saline and changes in $\mathrm{SR}_{\mathrm{aw}}$ as an index of response. An aerosolizer (Gauthier, Paris; particle size of $0.1-5 \mu \mathrm{m}$ ) delivering $0.0232 \mathrm{mg}$ of carbachol base per liter of air, was used to fill a spirometer bell with fresh aerosol. A two-way valve allowed inspiration from the spirometer and expiration outside the room. The subject was instructed to make from one to five inspirations of a fixed volume of aerosol (860 $\mathrm{ml}$ ) and to hold his breath for $4 \mathrm{~s}$ after each inspiration to ensure a large particle retention (12). The carbachol inhalation of one to five $860-\mathrm{ml}$ volumes represented a quantity of carbachol base varying from 0.02 to $0.1 \mathrm{mg}$. Because of inaccuracy inherent in any aerosol inhalation technique, the doses of carbachol actually deposited in the airways are probably different from those administered. However, since the inhalation technique was standardized, the error was thought to be constant throughout the different tests. After each carbachol inhalation $\mathrm{SR}_{\mathbf{a w}}$ was measured (mean of three determinations). The sequence-filling the spirometer with fresh aerosol, carbachol inhalation, and SR w determination-lasted about $2-4 \mathrm{~min}$ and was repeated until at least a $100 \%$ increase of initial $\mathrm{SR}_{\mathrm{aw}}$ was obtained. This procedure yielded a gradual increase in $\mathrm{SR}_{\mathrm{aw}}$, and the observer could easily modulate the intensity of the bronchial response by adjusting the magnitude of the carbachol inhalation. Since the progressive increase of $S_{\mathrm{aw}}$ with repetitive carbachol inhalations was not interrupted by allowing a return to base-line values between each carbachol inhalation and since carbachol is not metabolized by acetylcholinesterase, the dose-response curves obtained in this way were considered to be of the cumulative type (13).

Experimental protocols. Each subject was tested according to two different randomized protocols, between 2 and 6 p.m. on two separate days, with a 1-wk interval. Each test was run as follows: After determination of basal $\mathrm{SR}_{\mathrm{aw}}$ the subject was taken to the exposure room. The subject was left free to breathe either through the nose or mouth and remained seated in the room for $1 \mathrm{~h}$. Then, new determinations of $\mathrm{SR}_{\mathrm{aw}}$ were made and carbachol doseresponse curves were obtained as described. At one occasion, $\mathrm{NO}_{2}$ was present $\left(\mathrm{NO}_{2}\right.$ test $)$ in the air within the exposure room, whereas for the control test performed on a separate day, it was absent. The subject was unaware of the presence or absence of $\mathrm{NO}_{2}$. All 20 subjects of the $\mathrm{NO}_{2}$ group had a control test and a $\mathrm{NO}_{2}$ test with $0.1 \mathrm{ppm} \mathrm{NO}$. Subject 16 had two control tests (3-mo interval) and two $0.1 \mathrm{ppm} \mathrm{NO}_{2}$ tests (separated from the first control test 
TABLE II

Physical and Clinical Characteristics of the Asthmatics of the Control Group

\begin{tabular}{|c|c|c|c|c|c|c|c|}
\hline \multirow[b]{2}{*}{ Subject } & \multirow[b]{2}{*}{$\begin{array}{l}\text { Age }(y r) \\
\text { and sex }\end{array}$} & \multirow[b]{2}{*}{$\begin{array}{c}\text { Intrinsic (I) or } \\
\text { extrinsic (E) asthma }\end{array}$} & \multirow[b]{2}{*}{$\begin{array}{l}\text { Duration of } \\
\text { asthma }\end{array}$} & \multirow[b]{2}{*}{$\begin{array}{l}\text { Severity of } \\
\text { asthma* }\end{array}$} & \multirow[b]{2}{*}{$\begin{array}{l}\text { Cigarettes } \\
\text { per day }\end{array}$} & \multicolumn{2}{|c|}{$D_{100}$} \\
\hline & & & & & & $\begin{array}{l}\text { First } \\
\text { control }\end{array}$ & $\begin{array}{l}\text { Second } \\
\text { control }\end{array}$ \\
\hline & & \multicolumn{3}{|c|}{$y r$} & & \multicolumn{2}{|c|}{$m g$} \\
\hline 5 & \multirow{2}{*}{\multicolumn{5}{|c|}{ See Table I. }} & 0.24 & 0.24 \\
\hline 16 & & & & & & 0.94 & 0.78 \\
\hline 21 & $26 \mathrm{M}$ & $E$ (house dust) & 20 & 2 & 0 & 0.078 & 0.092 \\
\hline 22 & $16 \mathrm{M}$ & $E$ (house dust) & 12 & 1 & 0 & 0.10 & 0.11 \\
\hline 23 & $37 \mathrm{M}$ & I & 4 & 1 & 0 & 0.15 & 0.17 \\
\hline 24 & $25 \mathrm{~F}$ & I & 3 & 1 & 0 & 0.34 & 0.31 \\
\hline 25 & $41 \mathrm{~F}$ & E (grass pollen) & 14 & 1 & 0 & 0.35 & 0.34 \\
\hline 26 & $33 \mathrm{M}$ & $E$ (house dust) & 4 & 2 & 0 & 0.31 & 0.38 \\
\hline 27 & $19 \mathrm{~F}$ & I & $<1$ & 1 & 20 & 0.68 & 0.68 \\
\hline 28 & $24 \mathrm{M}$ & I & 2 & 1 & 15 & 1.27 & 1.57 \\
\hline 29 & $64 \mathrm{M}$ & I & 16 & 2 & 0 & 0.13 & 0.13 \\
\hline 30 & $20 \mathrm{~F}$ & $\begin{array}{l}\text { E (house dust, } \\
\text { cat dander) }\end{array}$ & 2 & 1 & 0 & 0.22 & 0.21 \\
\hline
\end{tabular}

* Grade 1, less than 8 days of dyspnea yearly; grade 2, less than 60 and more than 8 days of dyspnea yearly.

by 1 and 2 wk, respectively). Four subjects (subjects 2, $8,13,20)$, in addition to the $0.1 \mathrm{ppm} \mathrm{NO}_{2}$ test, underwent a test using $0.2 \mathrm{ppm} \mathrm{NO}_{2}$. In these cases, the order of the tests was also randomized.

With each subject serving as his own control, we compared the carbachol dose-response curves obtained on the control test to those obtained on the $\mathrm{NO}_{2}$ test to determine if $\mathrm{NO}_{2}$ changed the bronchial sensitivity to carbachol. To quantify the results we calculated from the curves the doses of carbachol causing a $100 \%$ increase of initial $\operatorname{SR}_{\mathrm{aw}}\left(\mathrm{D}_{100}\right)$.

Reproducibility of carbachol dose-response curves. To assess the spontaneous variability of carbachol dose-response curves we tested another group of 10 asthmatics (control group) with clinical histories and functional values similar to those of the subjects in the $\mathrm{NO}_{2}$ group. Two control carbachol dose-response curves were performed at a 1-wk interval and the $D_{100}$ values were calculated from the curves. In addition, two subjects (subjects 5 and 16) of the preceding group had two control tests. Table II shows that the $D_{100}$ was reproducible and that no systematic error appeared attributable to repetition of the procedure.

\section{RESULTS}

Individual results are shown in Fig. 1. As expected, the bronchial sensitivity to carbachol determined in the control test was variable among the individuals examined. Exposure to $0.1 \mathrm{ppm}$ of $\mathrm{NO}_{2}$ markedly increased the basal value of $S R_{a w}$ in only three subjects (subjects 3 , 6 , and 16). In others, SRaw was marginally increased, if at all. The effect of $0.1 \mathrm{ppm}$ of $\mathrm{NO}_{2}$ on the bronchial sensitivity to carbachol was also variable. In some subjects no clear change could be detected whereas in others the effect of carbachol on SRaw was enhanced. Doseresponse curves were shifted to the left with a resulting decrease in the $D_{100}$, and the slopes were usually steeper than the slopes of control dose-response curves. In subject 16, the enhancement of the carbachol effect by 0.1 ppm $\mathrm{NO}_{2}$ was reproduced on two occasions. When a concentration of $0.2 \mathrm{ppm}$ of $\mathrm{NO}_{2}$ was used it appears from Fig. 1 that this higher dose was $(a)$ no more effective than $0.1 \mathrm{ppm}$ in increasing the carbachol effect in subjects 2 and $8,(b)$ as effective as $0.1 \mathrm{ppm}$ in subject 13 , and $(c)$ more effective in subject 20 , in whom the $D_{100}$ was reduced from 0.94 to $0.42 \mathrm{mg}$. Exposure to $\mathrm{NO}_{2}$ did not change the TGV. Since the degree of bronchial obstruction produced by carbachol inhalation was similar before and after $\mathrm{NO}_{2}$ the accompanying increase in TGV was also similar in both occasions.

Fig. 2 shows the changes in $D_{100}$, for each subject, observed in this group of asthmatics ( $\mathrm{NO}_{2}$ group) after exposure to $0.1 \mathrm{ppm} \mathrm{NO}_{2}$ as compared to the spontaneous changes observed in the control group. For the NO, group, "test 1" refers to the $\mathrm{D}_{100}$ before $\mathrm{NO}_{2}$ and "test 2 " to the $\mathrm{D}_{100}$ after $\mathrm{NO}_{2}$. For the control group, the largest $D_{100}$ observed was chosen as test 1 and the smallest value as test 2 since the expected change in $\mathrm{D}_{100}$ after NOa exposure was a decrease. It appears from the figure that the spontaneous decreases in $D_{100}$ observed on two different tests in the control group were smaller than $20 \%$. Seven asthmatics of the $\mathrm{NO}_{2}$ group, being inside this $20 \%$ limit, were classified as " $\mathrm{NO}_{2}$ nonresponders" (subjects 2, 5, 7-9, 11, and 12), whereas 13 subjects having a decrease of more than $20 \%$ in $\mathrm{D}_{100}$ after $\mathrm{NO}_{2}$ exposure were classified as " $\mathrm{NO}_{2}$-responders" (subjects 1, 3, 4, 6, 10, and 13-20).

Table III shows the average effect of NOa exposure on initial $\mathrm{SR}_{2}$ and on control $\mathrm{D}_{100}$ in the $\mathrm{NO}_{2}$ group. 


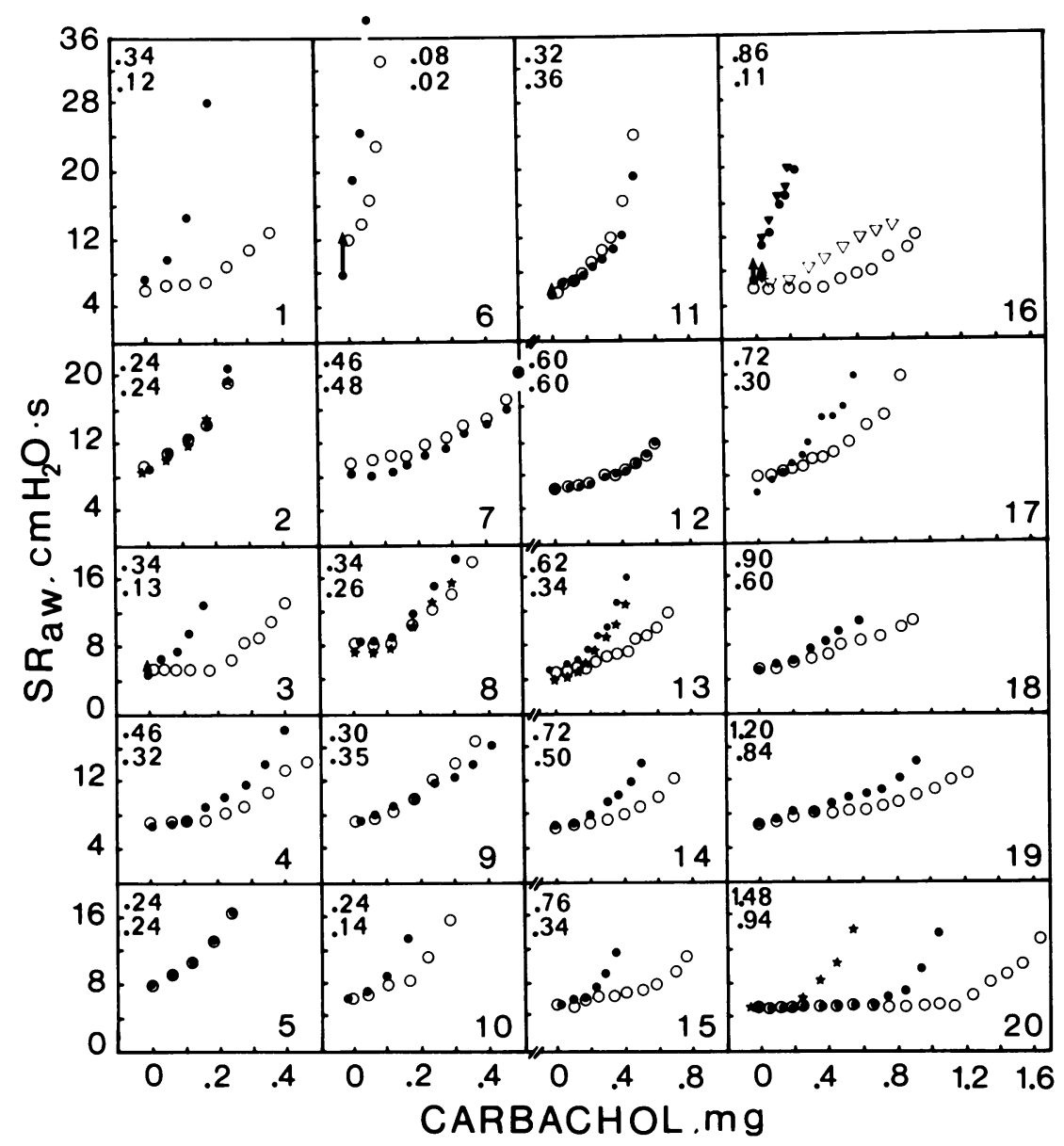

Figure 1 Effect of 1-h exposure to $\mathrm{NO}_{2}$ on the dose-response curves established in 20 asthmatic patients obtained by using cumulative doses of inhaled carbachol aerosol (abscissa) and measuring $\mathrm{SR}_{\mathrm{aw}}$ (ordinate) as an index of the response. Open symbols, control determinations; closed symbols, determinations after exposure to $\mathrm{NO}_{2}$; circles and triangles, $0.1 \mathrm{ppm} \mathrm{NO}_{2}$; stars, $0.2 \mathrm{ppm} \mathrm{NO}$. Each panel shows the result for one individual. The number in the right lower corner identifies the subject. The two numbers in the left upper corner indicate the dose of carbachol, calculated from the curves and expressed in milligrams, which causes a $100 \%$ increase of initial $S_{\mathrm{aw}}\left(\mathrm{D}_{100}\right)$; the upper number refers to control $\mathrm{D}_{100}$; the number below refers to $\mathrm{D}_{100}$ after exposure to $0.1 \mathrm{ppm} \mathrm{NO}$. The arrows indicate the changes in basal $\mathrm{SR}_{\mathrm{aw}}$ value observed in some subjects after exposure to $\mathrm{NO}_{2}$.

In the $\mathrm{NO}_{2}$-nonresponders group statistical analysis showed that the initial value of $\mathrm{SR}_{\mathrm{a}}$ was not significantly different between the two tests and that exposure to $0.1 \mathrm{ppm}$ of $\mathrm{NO}_{2}$ did not significantly change the initial value of $\mathrm{SR}_{\mathrm{aw}}$ nor the bronchial sensitivity to carbachol, expressed as $\mathrm{D}_{100}$. In the $\mathrm{NO}_{2}$-responders group it appeared that the inital value of $\mathrm{SR}_{\mathrm{aw}}$ was also similar for the two tests and that exposure to $0.1 \mathrm{ppm}$ of $\mathrm{NO}_{2}$ slightly, but significantly, increased the pre- $\mathrm{NO}_{2}-$ exposure value of $\mathrm{SR}_{\mathrm{aw}}$. After $\mathrm{NO}_{2}, \mathrm{D}_{100}$ was significantly reduced ( $45 \%$ decrease). From the comparison between responder and nonresponder groups it is apparent that the initial value of $\mathrm{SR}_{\mathrm{aw}}$, while slightly higher in the
$\mathrm{NO}_{2}$-nonresponder group was not significantly different from the value observed in the $\mathrm{NO}_{2}$-responder group for the control tests. In contrast, the initial value of $\mathrm{SR}_{\mathrm{a}}$ was significantly different in the two groups for the $\mathrm{NO}_{2}$ test. This difference may be attributable to subject 6, who had a much lower value of initial $S_{\mathrm{am}}$ on the $\mathrm{NO}_{2}$ test than on the control test. The mean control $\mathrm{D}_{100}$ was lower in the $\mathrm{NO}_{2}$-nonresponder group than in the $\mathrm{NO}_{2}$-responder although the difference was not significant. Thus, comparisons between the two groups showed that the $\mathrm{NO}_{2}$-nonresponders had initially a more severe airway obstruction and were more sensitive to carbachol than the $\mathrm{NO}_{2}$-responders. No obvious differ- 


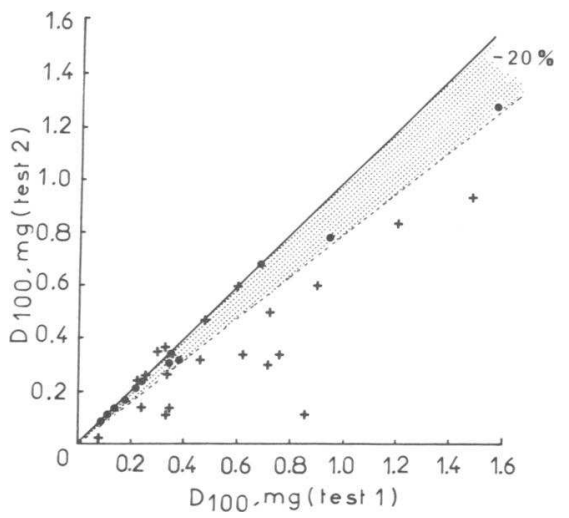

FIGURE 2 Changes in $\mathrm{D}_{100}$ in the $\mathrm{NO}_{2}$ group (20 asthmatics, crosses) as compared to the changes spontaneously observed in the control group (12 asthmatics, closed circles). For the $\mathrm{NO}_{2}$ group, test 1 represents the control determination of $\mathrm{D}_{100}$ and test 2 , the determination of $\mathrm{D}_{100}$ after $1 \mathrm{~h}$ exposure to $0.1 \mathrm{ppm} \mathrm{NO}_{2}$. For the control group, in which two control determinations of $D_{100}$ were made, test 1 represents the highest value and test 2 , the lowest value of $\mathrm{D}_{100}$. The solid line indicates the line of identity and the dotted line, a $20 \%$ decrease of test $1 \mathrm{D}_{100}$ as compared to test $2 \mathrm{D}_{100}$.

ences appeared between the two groups as regard to their physical characteristics (age, sex), the clinical history (duration, severity of asthma), the etiology of asthma (extrinsic or intrinsic), and the smoking history of the subjects tested.

\section{DISCUSSION}

The present results demonstrate that, in seitine asthmatics, exposure to low concentrations of $\mathrm{NO}_{2}$ causes a moderate - iो

a.

TABLE III

Effect of 1-h Exposure to $0.1 \mathrm{ppm}$ of $\mathrm{NO}_{2}$ on the $S R_{a w}$ and the Bronchial Sensitivity to Inhaled Carbachol Expressed as $D_{100}$ of a Group of 20 Asthmatics

\begin{tabular}{|c|c|c|c|c|c|c|}
\hline \multirow[b]{2}{*}{ Subjects } & \multicolumn{2}{|c|}{ Control } & \multicolumn{3}{|c|}{ After $0.1 \mathrm{ppm} \mathrm{NO}$} & \multirow{2}{*}{$\begin{array}{l}\text { Decrease } \\
\text { in } D_{100}\end{array}$} \\
\hline & Initial SR_w & $D_{100}$ & Initial $\mathbf{S R}_{\mathbf{s}}$ & $\mathrm{SR}_{\mathrm{am}}$ afer $\mathrm{NO}_{2}$ & $D_{100}$ & \\
\hline & $\mathrm{cm} \mathrm{H} \mathrm{H}_{3} \mathrm{O} \times \mathrm{s}$ & $m g$ & \multicolumn{2}{|c|}{$\mathrm{cm} \mathrm{H}_{2} \mathrm{O} \times \mathrm{s}$} & $m g$ & $\begin{array}{l}\% \text { of } \\
\text { control }\end{array}$ \\
\hline $\mathrm{NO}_{2}$-nonresponders $(n=7)$ & $\begin{array}{c}7.9 \pm 0.6 \\
(a)\end{array}$ & $\begin{array}{c}0.36 \pm 0.05 \\
(b)\end{array}$ & $\begin{array}{c}7.7 \pm 0.5 \\
(c)\end{array}$ & $\begin{array}{c}8.0 \pm 0.4 \\
\quad(d)\end{array}$ & $\begin{array}{c}0.35 \pm 0.05 \\
(e)\end{array}$ & 2 \\
\hline $\mathrm{NO}_{2}$-responders $(n=13)$ & $\begin{array}{c}6.6 \pm 0.5 \\
\text { (1) }\end{array}$ & $\begin{array}{c}0.66 \pm 0.10 \\
(2)\end{array}$ & $\begin{array}{c}6.0 \pm 0.2 \\
\text { (3) }\end{array}$ & $\begin{array}{c}6.9 \pm 0.5 \\
(4)\end{array}$ & $\begin{array}{c}0.36 \pm 0.07 \\
(5)\end{array}$ & 45 \\
\hline & & $t$ & $P$ & & $t$ & $P$ \\
\hline Horizontal comparisons made & (a) vs. (c) & 0.79 & $>0.05$ & (1) vs. (3) & 1.34 & $>0.05$ \\
\hline with Student's paired $t$ test & (c) vs. (d) & 0.70 & $>0.05$ & (3) vs. (4) & 2.30 & $<0.05$ \\
\hline & (b) vs. (e) & 0.08 & $>0.05$ & (2) vs. (5) & 5.93 & $<0.001$ \\
\hline Vertical comparisons made & (a) vs. (1) & 1.54 & $>0.05$ & (c) vs. (3) & 3.08 & $<0.01$ \\
\hline with Student's $t$ test & (b) vs. (2) & 1.96 & $>0.05$ & (e) vs. (5) & 0.08 & $>0.05$ \\
\hline
\end{tabular}

Mean values $\pm \mathrm{SE}$. The subjects having a decrease in $\mathrm{D}_{100}$ after $\mathrm{NO}_{2}$ of more or less than $20 \%$ are classified as $\mathrm{NO}_{2}$-responders or $\mathrm{NO}_{2}$-nonresponders, respectively. The level of statistical significance was chosen at $P<0.05$.

Effect of NO, on Asthmatics 
was observed only in one out of two subjects. This could be explained if the effect of $\mathrm{NO}_{2}$ is of the "all or none" type, i.e., increasing the dose has no effect until a certain threshold is reached where the effect occurs. Then, a further increase in dose yields no further effect until a second threshold is reached and so on. If the thresholds are variable among individuals one might think that the second critical threshold was reached only in one of the two subjects (subject 20).

It is also unclear why some asthmatics responded to $\mathrm{NO}_{2}$ and some others did not. Asthmatics have variable sites of airway obstruction, either central or peripheral (20), although the SRaw technique that we used reflects primarily changes in central airways. It is thus possible that any peripheral airway effect by $\mathrm{NO}_{2}$ was missed. However, we could not use other techniques to detect peripheral obstruction since they are either too complex for use with carbachol challenge (e.g., frequency dependence of compliance) or require maximum respiratory maneuvers (flow volume curves, closing volume) which modify the bronchial sensitivity of asthmatics (21). Differences in $\mathrm{NO}_{2}$ sensitivity between asthmatics could also be due to intrinsic individual variations in bronchial responses. Indeed such variations in $\mathrm{NO}_{2}$ effect were reported in normal subjects (22). If our previous hypothesis concerning critical threshold of $\mathrm{NO}_{2}$ is correct, we can assume that the first critical threshold was reached neither with $0.1 \mathrm{ppm}$ of $\mathrm{NO}_{2}$ for the $\mathrm{NO}_{2}$-nonresponders (seven subjects) nor with 0.2 ppm of $\mathrm{NO}_{2}$ in two subjects of this group. However, an alternative explanation is to consider that the $\mathrm{NO}_{2}$-nonresponders are not $\mathrm{NO}_{2}$ insensitive but rather $\mathrm{NO}_{2}$ hypersensitive. Thus, these subjects were exposed to urban concentrations of $\mathrm{NO}_{2}$ and one can assume they had already reached the first threshold and were already "carbachol sensitized." In these conditions it is possible that exposure to $0.1 \mathrm{ppm}$ of $\mathrm{NO}_{2}$ had no further effect if the second threshold of sensitization was not reached. This hypothesis is supported by the fact that the $\mathrm{NO}_{2}-$ nonresponders were, on average, more obstructive and more sensitive to carbachol on the control test than the $\mathrm{NO}_{2}$-responders.

Considering the practical consequences of our findings, we suggest that the incidence and severity of asthmatic attacks would be higher in areas with a polluted atmosphere, at least for some very sensitive subjects. The concentrations of $\mathrm{NO}_{2}$ that we used are encountered in many cities, mainly as a secondary product of car emissions. However, it is difficult to establish permissible threshold limit values since the sensitivity to $\mathrm{NO}_{2}$ varies among individuals. In addition, indoor exposure to $\mathrm{NO}_{2}$ produced by gas heaters and gas stoves may be more detrimental for many asthmatics than outdoor exposure. Furthermore, since one of the major sources of $\mathrm{NO}_{2}$ is cigarette smoke, it is interesting to notice that some asthmatics are smokers. However, it is known that the effects of cigarette smoke on airways are variable and complex (23) and it is possible that cigarette smoking has some acute favorable effects on airways, such as adrenergic stimulation, (24) which could balance the unfavorable ones.

\section{ACKNOWLEDGMENTS}

We are indebted to Dr. A. J. Lewis, who revised the English of our text, and to J. Fondarai for statistical consultations. The valuable technical assistance of Miss Geneviève Prezelin is likewise gratefully acknowledged.

This work was supported in part by a grant of the Institut National de la Santé et de la Recherche Médicale.

\section{REFERENCES}

1. Bates, D. V. 1972. Air pollutants and the human lung. Am. Rev. Respir. Dis. 105 : 1-13.

2. Bouhuys, A. 1974. Air pollution. In Breathing: Physiology, Environment and Lung Disease. Grune \& Stratton, Inc., New York. 385-415.

3. Kavet, R. I., and J. D. Brain. 1975. Reaction of the lung to air pollutant exposure. Life Sci. 15: 849-861.

4. Zweiman, B., R. G. Slavin, R. J. Feinberg, C. J. Falliers, and T. H. Aaron. 1972. Effects of air pollution on asthma: a review. J. Allergy Clin. Immunol. 50: 305314.

5. Simonsson, B. G., F. M. Jacobs, and J. A. Nadel. 1967. Role of autonomic nervous system and the cough reflex in the increased responsiveness of airway in patients with obstructive airway disease. J. Clin. Invest. 46: 1812-1818.

6. Booij-Noord, H., N. J. Grobler, N. G. M. Orie, and K. de Vries. 1969. Protective action of various drugs on provocation tests with respiratory irritants in patients with chronic non-specific lung disease (CNSLD). Respiration. 26: 182-195.

7. Nakazawa, H. 1969. Influence of sulfur dioxide $\left(\mathrm{SO}_{2}\right)$ on asthmatic patients. J. Jpn. Soc. Intern. Med. 58: 719730.

8. Dubois, A. B., S. Y. Botelho, G. N. Bedell, R. Marshall, and J. H. Comroe, Jr. 1956. A rapid plethysmographic method for measuring thoracic gas volume: a comparison with a nitrogen washout method for measuring functional residual capacity in normal subjects. J. Clin. Invest. 35 : 322-326.

9. Dubois, A. B., S. Y. Botelho, J. H. Comroe, Jr. 1956. A new method for measuring airway resistance in man using a body plethysmograph: values in normal subjects and in patients with respiratory disease. J. Clin. Invest. 35 : 327-335.

10. Clement, J., and K. van de Woestijne. 1971. Resistance or conductance? Compliance or elastance? J. Appl. Physiol. 30: 437-439.

11. Saltzman, B. E. 1954. Colorimetric microdetermination of nitrogen dioxide in the atmosphere. Anal. Chem. 26: 1949-1955.

12. Palmes, E. D., C-S. Wang, R. M. Goldring, and B. Altshuler. 1973. Effect of depth of inhalation on aerosol persistence during breath holding. J. Appl. Physiol. 34: 356-360.

13. Van Rossum, J. M. 1963. Cumulative dose-response 
curves. Technique for the making of dose-response curves in isolated organs and the evaluation of drug parameters. Arch. Int. Pharmacodyn. Ther. 143: 299330.

14. Islam, M. S., E. Vastag, and W. T. Ulmer. 1972 Sulphur-dioxide induced bronchial hyperreactivity against acetylcholine. Int. Arch. Arbeitsmed. 29: 221-232.

15. Matsumura, Y., K. Mizuno, T. Myamoto, T. Suzuki, and Y. Oshima. 1972. The effects of ozone, nitrogen dioxide, and sulfur dioxide on experimentally induced allergic respiratory disorders in guinea-pigs. IV. Effects on Respiratory Sensitivity to inhaled acetylcholine. $\mathrm{Am}$. Rev. Respir. Dis. 105: 262-267.

16. von Nieding, G., and H. Krekeler. 1971. Pharmakologische Beeinflussung der akuten $\mathrm{NO}_{2}$-Wirkung auf die Lungenfunktion von Gesunden und Kranken mit einer chronischen Bronchitis. Int. Arch. Arbeitsmed. 29: 55-63.

17. Widdicombe, J. G., and G. M. Sterling. 1970. The autonomic nervous system and breathing. Arch. Intern. Med. 126: 311-329.

18. Nadel, J. A., H. Salem, B. Tamplin, and Y. Tokiwa. 1965. Mechanism of bronchoconstriction during inhalation of sulfur dioxide. J. Appl. Physiol. 20: 164-167.
19. Douglas, J. S., R. B. Helgerson, and A. Bouhuys. 1972. Interaction of humoral agents and regulation of airway smooth muscle responses (ASMR). Fed. Proc. 31: 336. (Abstr.)

20. Despas, P. J., M. Leroux, and P. T. Macklem. 1972. Site of airway obstruction in asthma as determined by measuring maximal expiratory flow breathing air and a helium-oxygen mixture. J. Clin. Invest. 51: 3235-3243.

21. Orehek, J., P. Gayrard, C. Grimaud, and J. Charpin. 1975. Effect of maximal respiratory manoeuvres on bronchial sensitivity of asthmatic patients as compared to normal people. Br. Med. J. 1 : 123-125.

22. Hackney, J. D., F. C. Thiede, W. S. Linn, and E. E. Pedersen. 1973. Effect of short-term $\mathrm{NO}_{2}$ exposure in lung function in normal human subjects. Chest. 64: 395. (Abstr.)

23. Gayrard, P., J. Orehek, C. Grimaud, and J. Charpin. 1974. Bronchoconstriction due à l'inhalation de fumée de tabac: effets comparés chez le sujet normal et l'asthmatique. Bull. Physio-Pathol. Respir. 10: 451-461.

24. Zuskin, E., C. A. Mitchell, and A. Bouhuys. 1974. Interaction between effects of beta blockade and cigarette smoke on airways. J. Appl. Physiol. 36: 449-452. 